\title{
REVIEW
}

\section{A review on homogeneity across hydrological regions}

\author{
Safieh Javadinejad
}

Water Resource Engineering, University of Birmingham, Birmingham, B152TT, UK

\section{Check for updates}

Correspondence to: Safieh Javadinejad, Water Resource Engineering, University of Birmingham, Birmingham, B152TT, UK;

Email: javadinejad.saf@ut.ac.ir

Received: June 20, 2021;

Accepted: October 7, 2021;

Published: October 15, 2021.

Citation: Javadinejad S. A review on homogeneity across hydrological regions. Resour Environ Inf Eng, 2021, 3(1): 124-137.

https://doi.org/10.25082/REIE.2021.01.004

Copyright: () 2021 Safieh Javadinejad. This is an open access article distributed under the terms of the Creative Commons Attribution License, which permits unrestricted use, distribution, and reproduction in any medium, provided the original author and source are credited.

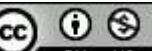

\begin{abstract}
Hydrologic classification is the method of scientifically arranging streams, rivers or catchments into groups with the most similarity of flow regime features and use it to recognize hydrologically homogenous areas. Previous homogeneous attempts were depended on overabundance of hydrologic metrics that considers features of variability of flows that are supposed to be meaningful in modelling physical progressions in the basins. This research explains the techniques of hydrological homogeneity through comparing past and existing methods; in addition, it provides a practical framework for hydrological homogeneity that illustrates serious elements of the classification process.
\end{abstract}

Keywords: classification process, homogeneous, hydrologic classification, physical processes, modeling

\section{Introduction}

Hydrologists have applied hydrological homogeneity in order to assign specific streams and rivers into a larger spatial setting aimed at expanding transferability between rivers in a similar hydrologic class [1]. This process has frequently been used in order to expand visions from well-gauged areas to ungauged or thinly gauged areas or rivers [2]. Normally, only particular elements of the flow regime are involved (e.g. flood series). Regionalisation examinations to forecast streamflow treatment in ungauged basins often contain a number of models of regression established on various categories of particular hydrologic information at gauged stations [3]. Therefore, by separating surveying areas into homogeneous classes which can display alike hydrologic features records can be implied with more accuracy, and models of regionalisation are established based on basin features with higher assurance [4].

Evaluating hydrological homogeneity can be applied in environmental flow valuation regarding the improvement ecological sustainability for water organization. Because recent attention concentrated on the preservation arrangement of ecosystems of freshwater for biodiversity and hydrological homogeneity analysis at regional scale can be a valuable tool to guide organization of streams, rivers or whole basins through characteristic of flow regimes, and biological groups [5].

There are thee extensive groups of hydrologic category that assist to define regime of flow likenesses between rivers: those conferring to contiguity of features of hydrologic condition, geographic or environmental elements [6]. Geographical regions are recognized as established upon political, managerial, river and climate boundaries [7]. The defined areas have been placed in near geographic contiguity to one alternative, but this regularly cannot guarantee that the areas would be hydrological homogenous.

Another method which is described is grouping areas based on elements of environment that are supposed to make alike hydrological reactions largely. This shows a reasonable method for grouping hydrological features that has regular individual geographical features and illustrated through a mosaic outline of hydrologic categories of the landscape [8].

Several physical-established (or geomorphic) categorization of rivers carried out, containing some features of climate, geology, topography [9], and also mixed hydro-geomorphic typologies [10-12]. The categorizations are popular, however cannot reveal single hydrological difference since they contain further broad values regarding the origins of spatial difference in environmental features of rivers and streams [13]. To resolve these problems, defining patterns in hydrologic character are recognised directly via methods that are established on empirically features that can apply hydrologic metrics explaining several elements of the flow regime [14]. Therefore, hydrologic categorization systems attempt to make instruction to integrally compound flow data through recognizing and distinguishing likenesses between rivers. These are corresponding to a set of analytic hydrologic characteristics that can change spatially through 
the topography [15]. The empirical techniques for hydrologic categorization attempt to focus on this sector.

Numerous hydrologic features are in the natural flow regime. The hydrologic features involve the timing of severe flows, seasonal patterning of flows, and irregular flows. Also seasonal flow in daily time step, and yearly flow changeability, the frequency, probability and period of floods/droughts and rates of alteration is considered [16].

Therefore, the efforts in previous classification depended on excess of hydrologic metrics which were used for flow variability features which are very important in forming ecological and physical progressions in ecosystems [17]. A lot of these metrics verified in order to greatly be appropriate for grouping hydrologic features. Furthermore, the features of the hydrologic regimes can normally effected through human actions for instance river regulation through weirs, and also it is too sensitive to global climate alteration $[18,19]$. Researchers employed numerous statistical methods and applied several hydrologic metrics in efforts to improve categorizations of hydrologic features at different spatial scales [20]. For instance, at scales of universal or continental the efforts, principally concentrated on particular characteristics of the hydrograph like seasonality, flood conduct or low flow features, although local categorizations applied a larger group of hydrologic metrics [21].

Since there is a requirement for measuring flow similarities amongst rivers and to record their dispersal across hydrologic circumstances [2], ecologists should focus on a lot of proper statistical methods by applying various set of protocols to manage their hydrologic categorisation [20]. Significant efforts have been carried out to examine and improve proper methods to hydrologic categorization throughout the last two decades. Therefore, various techniques should be applied and single method cannot determine conventional outcome, universally.

Subsequently, most researchers should develop new statistical approach to tackle unexpected classification problems [22]. Various hydrological homogeneity methods are used in the past in order to attain hydrological categorisation and regionalisation. The methods contain: "hierarchical and flat clustering algorithms, self-organising maps (SOM), multivariate ordination and hard and soft categorisation algorithms for instance fuzzy clustering and Bayesian categorization" [?].

This study reviewed the past and present several techniques available and the necessary information and essential progressions in order to fulfil several statistical hypothesis and requirements. Also this paper employed a protocol for categorisation that can solve troubles of data quality and commensurability and selection of categorisation method and assessment of consequences. In addition, this research concentrated on run off quantities (or flood occurrences) in order to examine regional hydrological homogeneity, since the changeability in the run off data are fewer in contrast with other hydrological factors (like precipitation quantities). This can happen since:

a. the changeability in precipitation quantities mostly related to time-spatial features

b. The alterations in skewness of precipitation quantities are more than run off quantities

c. the influences of climate alteration on precipitation is higher than the impact of climate alteration on run off quantities (for instance the influence of winds are fewer on run off in contrast with the influence of winds on precipitation).

\section{Material and methods applied for hydrologic catego- rization}

The scheme of hydrologic categorization is based on allocated parameters (i.e., rivers, streams basins) and used empirical method to categorize hydrological features in order to rise the likeness amongst members of each class and decline the likeness amongst classes [24]. Subsequently, there are several paths to distinguish magnitude and changeability of flow, thus examining hydrologic metrics applying several techniques which have applicable processes in order to identify likenesses or alterations amongst given streams and rivers [2]. There are various methods in order to distinguish classes of river and arrange them into a categorization of hydrologic features [25]. The methods are also differ in output possessions like understanding the groups are hierarchical or flat, recognizing boundaries amongst groups are difficult (i.e., defined) or soft (i.e., fuzzy), and understanding the ability of rivers that may fit to one or extra classes (explained in detail below).

A significant trouble met when applying cluster examination for hydrologic categorisation is the plethora of numerous connection algorithms and distance processes accessible [26] Unfortunately, several clustering methods used to the similar groups of data can regularly make configurations that are considerably dissimilar [27]. This happen as a result of the selection of a clustering technique indirectly inflicts a configuration on the population and is often equal to describing a configuration [28]. Thus, the selection of statistical method used in hydrologic 
classification is significant. So, this paper makes a review of various approaches that can apply to improve classifications of hydrologic features in the past, and also explains alterations among difficult versus soft categorizations.

\subsection{Hierarchical and flat clustering algorithms}

Both hierarchical and flat clustering algorithms can apply to improve hydrologic categorizations. Hierarchical clustering progresses repeating through either mixing minor clusters into greater ones (agglomerative), or through severe greater clusters to minor ones (divisive) to make a categorization of groups normally displayed as a "dendrogram" of clusters (a dendrogram is a tree diagram regularly can apply to explain the organization of the clusters created through hierarchical clustering). Flat clustering methods recognize clusters of equal distinction, and therefore cannot be characterized in a hierarchy. Particular algorithms can be adjusted to make hierarchical or flat categorizations.

Latt et al. [3] presents a great overview from a statistical viewpoint. Chuan et al. [29] define eight popular algorithms in order to make suitable hierarchical clustering of rivers in regards to their flow regimes:

(1) single connection or adjacent neighbor;

(2) comprehensive connection or farthest away neighbor;

(3) average connection (UPGMA);

(4) biased average connection;

(5) centroid;

(6) median or biased pair-group centroid;

(7) density or k-connection;

(8) Ward's algorithm.

The k-means algorithm can be used in discordant clustering method for non-hierarchical categorization. The algorithm categorizes cases regarding to Euclidian distance from preliminary, arbitrarily selected cluster centres of a prearranged number. Hence, it repeatedly re-describe cluster centres by way of the averages of the items in the newest cluster, until cases no lengthier alter membership. The technique can be proficient for countless datasets, and usually outcomes are sufficient, even though bias of the primary cluster centroids should examine. Hierarchical and flat clustering techniques may apply together to develop hydrologic categorisation (called hybrid clustering). For instance, Chuan et al. [29] employed a partitioned clustering progression in order to distinguish groups of alike catchments through improving the clusters obtained from "agglomerative hierarchical clustering algorithms" applying the k-means algorithm. Also, Belletti et al. [30] examined outputs of a hierarchical, average-connection algorithm to assist distinguish an ideal amount of clusters for succeeding flat classification applying k-means. Describing the number of clusters is a trouble characteristic for the whole predictable clustering methods.

The amount of clusters for flat algorithms, should organise beforehand the arrangements of input data has been assessed. Selection of the grade of cluster difference among level is very difficult. Many techniques for developing the number of clusters considered in the previous studies.

\subsection{Self-organizing maps}

Lin and Wang [31] applied SOM as a basis to perform cluster assessment and bias investigation of hydrological elements in one step as a novel and capable technique for hydrologic categorisation.

SOM which is related to cluster and discrimination examination (SOMCD) can create three maps in one case in order to apply in a categorisation.

The mass and distinction maps might be used in order to allocate unidentified basins to categorizes at one period, removing the step of post-clustering diacritical investigation for individual unidentified basin.

In addition, the potential to explain the amount of clusters with various resolutions from the aspect and mass maps can deliberate like the best benefit for the technique.

\subsection{Multivariate ordination}

Multivariate ordination approaches, comprising principal components analysis (PCA) and main coordinate investigation, can apply to develop hydrologic categorisation. PCA can comprise a mathematical progression which can alter an amount of associated parameters into a (minor) amount of non-associated parameters known as "principal components". 
The initial principal component can be used on behalf of understanding changeability in the data and individual subsequent element can be used for the remaining changeability [32].

In several functions, the arrangement scores from a minor amount of principal components can hold and afterward can cluster in order to distinguish rivers with parallel flow regimes.

\subsection{Hard versus soft classification}

Clustering algorithms are used for both hard and soft (i.e., fuzzy) categorizations. A hard clustering technique can establish for the supposition of characteristic of vectors which may separate into non-overlapping clusters through distinct borders amongst them. Individual characteristic of vector can assign to single cluster with a grade of membership equivalent to union. Also, a basin can categorise as a fitting to a cluster on the centre of distance (difference) amongst the basin and the cluster centroid in the various dimensional area of features demonstrating the flood reaction of basins.

Chuan et al. [29] have provided clear description of hard clustering algorithms in regionalization. The most basins can be similar to various basins and thus, assigning a basin to one area (cluster) or another possibly cannot be justified. Thus, distinguishing areas with ambiguous boundaries amongst them are appropriate, contrasted to hard districts with clear boundaries like in the condition of hard clustering. The fuzzy principle which comprises investiture categorisation and clustering examination is a normal approach to indicate such as statuses.

"Fuzzy partitional clustering" permits a basin to fit to whole areas concurrently with a particular grade of membership. The dispersal of basin membership among the fuzzy clusters states the power with which the basin fit to given area. The information of this dispersal is specifically valuable to recognize unclear basins. A level to highest membership principles may use in order to develop crisp, vector-established depictions from raster, fuzzy categorizations. Goyal and Gupta [44] showed the complicated procedure connections operating morphology of channel and the insufficiencies of standard stream categorization approaches, fuzzy depictions of in-stream environment display an attractive substitute.

Additional fuzzy subdivided technique is "Bayesian combination modelling". The observed distribution of data is simulated by means of a combination of a limited amount of element distributions in this method, so as to distinguish the quantity of distributions, their elements, and target memberships [45]. The method based on completely probabilistic and uncertainty that may obviously described in regards to characteristic of data, group arrangement and the last categorization selected. Various reasonable categorizations has been made, which subsequently have been graded on their assessed borderline probabilities in order to choose the most economical classification which is certified to take the maximum subsequent probability; the probability of the model take place accurate assumed the data [45].

Table 1 shows some samples of hydrologic categorization of flow regimes. Flow regime assigns: "magnitude $(\mathrm{M})$, frequency $(\mathrm{F})$, duration $(\mathrm{D})$, timing $(\mathrm{T})$, rate of change $(\mathrm{R})$. Temporal scale includes daily (D), monthly (M), annual (A)". The table indicates the outcomes of the previous studies.

Table 1 Examples of hydrologic classifications of riverine flow regimes

\begin{tabular}{lllll}
\hline $\begin{array}{l}\text { Scale of } \\
\text { Spatial }\end{array}$ & Site & $\begin{array}{l}\text { Flow } \\
\text { Attributes }\end{array}$ & $\begin{array}{l}\text { Scale of } \\
\text { Temporal }\end{array}$ & Method for Classification \\
\hline Catchment & $\begin{array}{c}\text { Rhineland-Palatinate } \\
\text { (Germany), Wüstebach }\end{array}$ & M,F,D,T & D,M,A & $\begin{array}{l}\text { Principal component analysis, Hierarchical, cluster } \\
\text { analysis, Fuzzy model }\end{array}$ \\
\hline Local & Queensland, Khartoum & M, D,T,R [34] & D,M & $\begin{array}{l}\text { Principal component analysis, agglomerative cluster } \\
\text { analysis }\end{array}$ \\
\hline National/continental & Europe, Africa, Asia, America & M,T & D & $\begin{array}{l}\text { Principal component analysis, Hierarchical, cluster } \\
\text { analysis, flow regime class discriminating }\end{array}$ \\
\hline [36] [37] \\
[38] [39]
\end{tabular}

\section{Results}

\subsection{A structure and protocol for hydrological classification}

A quantitative progression should include in hydrologic categorization, clear, easy to use for indecision and for changeability at several scales of temporal and spatial, and has ability to 
explain class boundaries and has fair class membership and enough data on the analytic hydrologic features of each group. Significant parameters for making the hydrological classification is shown in the Figure 1.

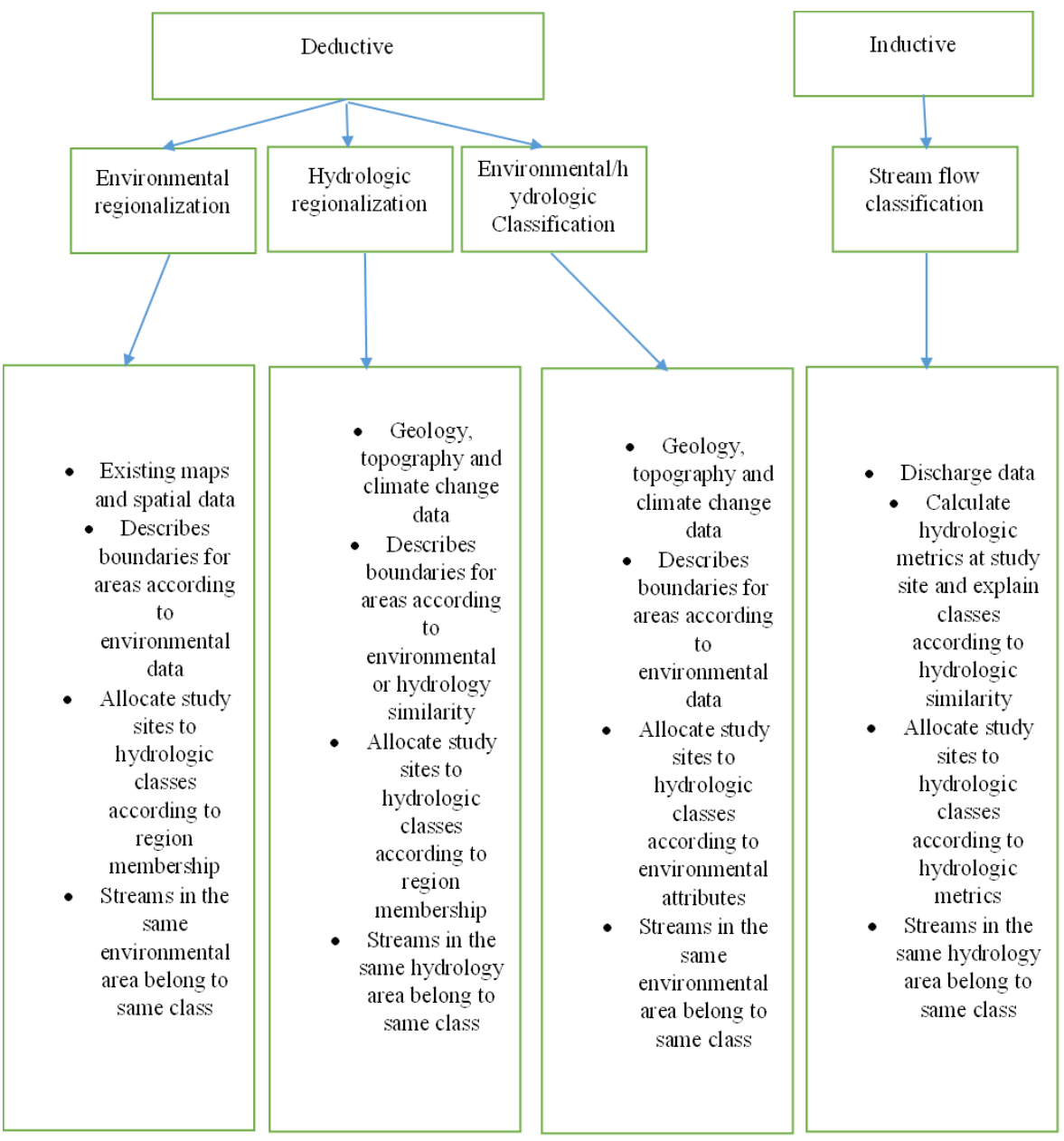

Figure 1 Important approaches to hydrologic classification

Unique strategies for attaining this purpose are displayed in below:

(1) Illustrate the research aim, topographical district of concentration and aim of hydrologic categorization

(2) Attain and calculate data of hydrologic features

a. Estimation of available discharge data (gauged against modelled data, temporal scale in terms of daily, monthly or annual, time episode, and physical exposure).

b. Choose applicant which has established for gauges (for the data of gauged discharge).

c. If goal is to group regimes of natural flow, so choice of gauges which did not affect by anthropogenic aspects (for example dams, withdrawal of water, land use) applying best accessible knowledge (for example spatial outlines of land use, storage and dam site and aspects, proficient awareness and contribution from water administrators, etc.) can be helpful.

d. Assess feature of discharge data (such as lost data, weak quality calculation recordings that can display by quality codes) and remove gauges with lost data and inadequate gauge recordings.

e. Prove reliability of units of discharge determination between gauges.

f. Assess accessible discharge data for temporal episode and period for individually gauge.

g. Create standards for gauges approval (i.e., smallest against fixed record duration, entirely overlapping against moderately overlapping episode of record, episode of historical data to comprise specific periods, like periods comprising considerable alterations in climate).

h. Assess features of topographical places of gauges to certify acceptable spatial exposure (in order to show better climate characteristics).

i. Evaluation possible for comprising supplementary gauges can do through the items in below, if the spatial analysis do not appear acceptability: 
- declining the approval standards.

- assessing absent data in the time series of discharge through applying linear interpolation for small episodes, and general linear regression used for lengthier episodes, or some additional suitable method.

Also, reducing the approval standards will decline the commensurability of gauges, and assessing absent data can raise the amount indecision of data of flow. All the items will effect on correctness of categorization outcomes (while some hydrologic metrics are very vulnerable to record interval and period overlay than others).

(3) Select hydrologic metrics to involve in the categorization of hydrologic and the choice of metrics based on research objectives. Choosing various metrics to distinguish whole aspects of the flow regimes, or specific metrics of recognized/assumed environmental significance [2].

a. usual environmental basis: group of metrics in order to distinguish the whole flow regime.

b. particular environmental basis: individual metrics of recognized environmental significance for particular species, society, population or environment possessions.

c. driver basis: metrics that can delicate to an ecological or human provider of importance (e.g., climate alteration, change stream/river regulation, urban development).

d. Choice based on time-based particle of flow data.

e. Choice based on proposed software that can be applied for measuring metrics and feasible ability of the investigator. Software preferences contain dedicated hydrologic software.

f. Choice depends on measuring statistical dismissal between metrics via single variable and multivariate methods. The outcomes can notify inconstant choice and dimensionality decrease if multi-collinearity between metrics need to be analyzed.

g. Without choice. Hydrologic categorization can progress using the raw discharge time series.

(4) Calculate hydrologic metrics

a. Estimate the hydrologic metrics for individual record of flow regarding to results explained in previous step.

b. Analyzing data records for outlet of hydrologic gauges which influenced through human actions via:

c. Considering analytical maps and expressive statistics.

d. performing indirect investiture, mapping "ordination scores of gauges" in 2D space and examining results of natural flows, adjusted flows, or amount of errors.

e. Calculating average daily flow in contradiction with basin region (it means stations with minor water release than anticipated for a particular size of basin can be analyzed through water withdrawal).

f.Remove stations in compulsory condition.

g. Reduce scale-reliance of discharge greatness metrics (if necessitated, established on goals of the study) through normalising metrics via basin area or average of flow in daily scale.

(5) Implement the hydrologic categorization

a. Select method for statistical analysis reliant on goals of categorisation, software and skill of an investigator.

b. Determine which hydrologic metrics can comprise in categorisation examination:

- entirely metrics of flow.

- subclass of metrics explaining individual elements of flow regime (this determination relates to the purpose for categorisation.

- consider the whole quantity of flow metrics to a minor group of great-data, non-surplus flow metrics.

- choice of metrics can relate to statistical hypothesis/necessities (type of data, ordinariness, etc.) of categorisation method.

c. Determine the necessity of metric conversions/normalisations.

d. Decide on proper distance/likeness calculation.

e. Considering assessment of categorisation.

f. Explain clusters, and select some of the groups (i.e., clusters) of hydrological features, group participation, and likelihoods of group participation.

g. Investigate categorisation consequences for deviation and abolish stations if it is essential.

(6) Explain the hydrologic categorisation

Illustrate hydrologic features of hydrologic groups, mathematically, statistically, explicitly, and orally.

Assess geographic dispersal of station group participation (e.g., applying GIS).

Justify the categorisation simulation with applying an objective dataset comprising stations which not comprised in the categorisation or established on a group of factors for environmental that can illustrate individually station that can deliberate the greatest significant for modelling the features of flow regime (specifically the consequences of a physical-established categorisation). 
According to the previous explanations and methods that mentioned above, hydrological classification for global is shown in Figure 2.

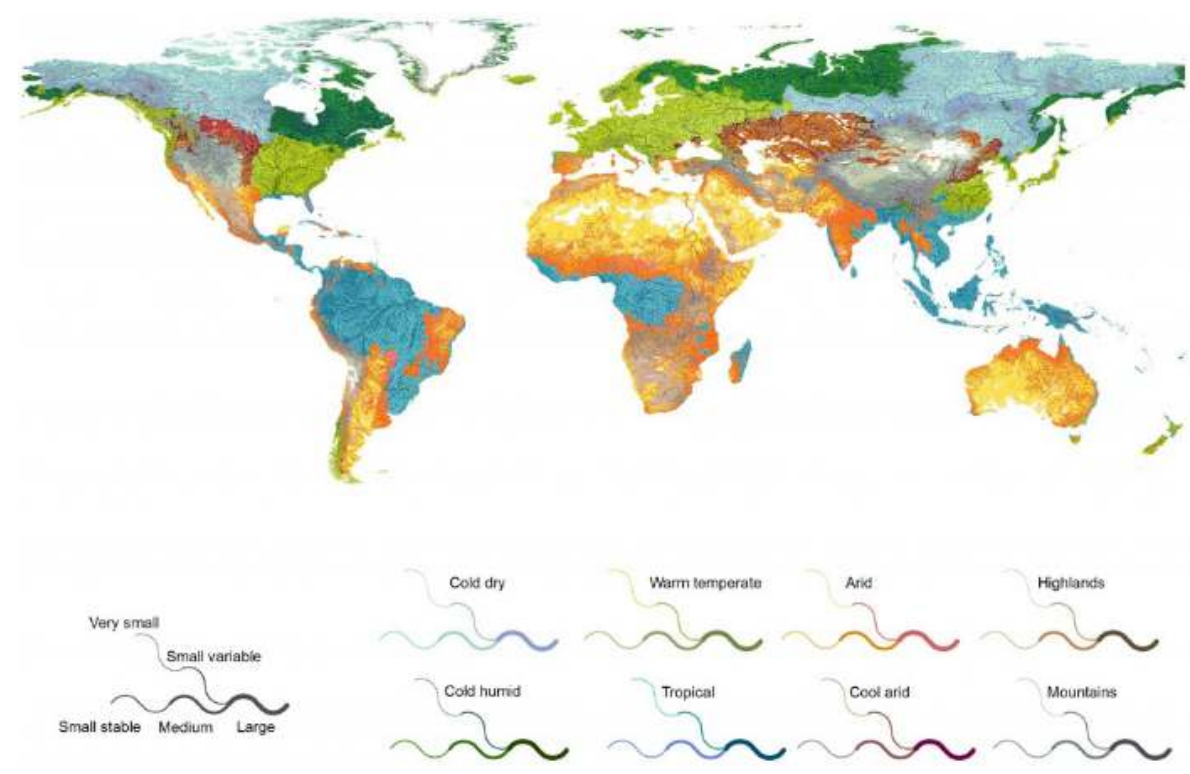

Figure 2 Global hydrological classification (Globalhydo Lab, 2020)

\subsection{The development and application of hydrological categoriza- tion in Australia}

Previous works studied hydrological categorisation of Australian rivers at diversity of spatial scales [35]. These performances are essential because for analysing data of hydrological feature for non-station districts to support water organisation and water engineering projects (like dam and bridge structures).

A number of others previous researches did not contemplate data of real daily flow, however deliberated data for environmental features that perform as representations for discharge and regularly simulate a restricted subclass of hydrological factors (specifically series for maximum and minimum flows). Applying factors for hydrological features which did not apply normally through environmentalists or which did not instantly distinguish for processes of ecological application [35]. A few works considered the ecological aspects. Some efforts mentioned to regionalisation instead of categorisations as the basic goal for the origin of mathematical associations which can illustrate conduct of feature of hydrological to specify region in Australia.

\subsection{Categorization at basin scale}

At first, a few previous studies which have assessed eco-hydrological difference inside a stream and in a catchment are explained as below.

Koch et al. (2016) [34] analysed a categorisation of data of discharge for different sites inside a specific river which creates a main water supply of a specific river in downstream. In their research, modelled daily flow data for two water supplies improvement scenarios for 73 years is used. The scenarios were:

(1) no improvement scenario;

(2) existing water supply improvement scenario to compute flow statistics and focus on the most significant aspects of the flow regime for three time-based scales.

A specific matrix can use for categorization which known as "UPGMA" and ordination assessed with applying the Gower index which has normalises units through each parameter.

Previous normalisation for magnitude parameters (which depends on catchment area and median daily flow) was not really suitable.

Additional correlation examination is not done earlier than multivariate evaluations in previous works, however all factors need to be analysed individually as well. The correlation usually is among purposes and characteristics in consecration area.

Some classes of places (with modelled stations) designed through the categorisation associated with the downstream point in an arrangement regarding to geographical alterations in hydrological features categorisation succession for the research region. 
Though this consecutive association of flow regime and physical features can rise for the reason that magnitude variables have not scaled to develop fundamentally dimensionless earlier than insertion in the multivariate investigations. The collaboration amongst streamflow and waterway geology can obtain the system principally through regard to space alteration in time of the regime. The several sets of temporal factors relate to the time scales in several geomorphic zones which can effect on flow regime and hydrology categorisations.

In another example, the spatial alteration in the hydrologic system of a specific river in Australia evaluated by Jarihani et al. (2017) [46]. Nineteen years episode of daily flow information for 26 gauges in the river basin are assessed in the study.

Gauges which have been categorised a priori, established on physical features (such as geographic characteristics, sub-drainage membership and type of the river) and a fairly concordant outline of spatial alteration in freshwater structure. Also the study concentrated on spatial alteration in hydrological changeability and the choice of metrics which can apply. In addition, the study used some specific statistics parameters such as CV of daily, monthly and yearly flows, threshold of "yearly exceedance frequency of a minimum flow", metrics calculating expectedness (of monthly maximum, minimum, monthly sums and ratio of up to down flows (in daily scale) in order to understand changeability of flows through several time episodes. Mean yearly flows did not contain in the analysis since this parameter was not normalised. Average annual and daily flows could involve however the metrics did not normalized preceding to examination.

Individual proper investigation of termination did not perform, however a survey of the association amongst the region of catchment and metrics for hydrological feature proved that among whole stations, just average yearly and daily streamflow depended to the region of catchment. Nevertheless, inside some of the initial modelled groups, catchment area related with up to six factors (especially with mean of annual flow). Discriminant performs analysis (stepwise) applied to assess alteration in discharge regime for the catchment. Twelve of the 16 factors, (such as mean annual flow), fluctuated considerably among groups and so great similarity was observed amongst flow regime and position in the catchment (100\% effective categorisation). Spatial alteration in flow regime depended on different gradients. In addition, the changeability in minimum, maximum and mean daily flows depended on spatial alteration in rainfall and geology. The hydrological categorisation was analysed with regard to the limitations in changeability in flow systems examinations.

A method based on GIS maps applied in Iran in order to categorise stream-aquifer connectivity with different spatial characteristics Naghibi et al. [47]. In their work, classification analysis for stream-aquifer connectivity examined with respect to two important aspects:

(1) economically parameters and water allocation.

(2) ecologically factors such as environmental flow and organisation of water quality.

In addition they obtained four important parameters which effect on hydrological categorisation which includes:

(1) Water table depth: The data generated from current borehole and also relevant agencies.

(2) Sediments of stream bed: The main data generated from natural dataset for hydraulic conductivity for soil flooded.

(3) Geology: The dataset generated from current lithology maps from relevant agencies.

(4) Geomorphology: The data generated from multi maps especially DEM maps.

The results of all the four parameters showed the connectivity index and the values categorised in low, medium and high level. The categorisation was helpful for ecological organisation (although it did not significantly improve), and also the classification was useful for understanding groundwater/surface water interfaces [48].

Available information and the resolution (grain) of the data are the most significant parameter which can effect the development of the method. For example in Northern Australia where geology has not recorded greatly, so using the method will be difficult. In the Lake Eyre basin, in order to examine hydrological classifications (include groundwater flow regimes and characteristics), map-based GIS technique is used [49].

While several data did not mix to generate a formal categorisation for flow regimes in the catchment, however, improvement of a simulation in order to illuminate space alteration in total water stability was done to analyse hydrology similarities in the basin.

In Macleay Valley basin in New South Wales, a hydrological categorisation examined with using map-based GIS technique (which combined with examinations improved for numerical taxonomy). Also associations among basin characteristics and stream flow analysed in order to extend the basin (from neighbours basins) Lawson et al.(2015) [50]. The hypothesis for making the categorisation was that hydrologic similarity depended on geography likeness and rainfall likeness significantly (however it is also depended on all available information). 
In another study [51], similarity in hydrological categorisation analysed with applying a mixture of the "Gower and Bray Curtis" processes and the algorithm of "NEWCLAS", so different analytical approaches compared. They discovered that there is considerable associations between the mixed landscape (landscape categorised into five groups: lithology, topography, land cover, lithology and wetland type) and rainfall patterns and several features of hydrology for some gauged stations in the catchment, so it could validate the connection between all these features and stream flow.

\subsection{Categorization at regional scale}

In the districts of South-Eastern Australia, various categorisation performed. Multivariate techniques applied in order to spatially simulated stream flow and categorise similarity in flow regime at the regional scale of Tasmanian Rivers (Velasco-Forero and Jolly, 2015).

In addition daily flow data applied to categorised hydrological similarity for 77 gauges inside 69 basins for duration of 15-81 years (Velasco -Forero and Jolly, 2015). In their work, greatness variables did not create dimensionless earlier than examination and proper investigation of redundancy did not perform.

Also principal component's examination and regression investigation applied to estimate the correlations between many parameters and mean of annual stream flow. Four main groups obtained through categorisation. In addition, spatial characteristics which effect on the categorisation related to topography and climate. The four groups include:

- Group one showed streams that placed on the north-western coastline area of Tasmania with average runoff values of $410 \mathrm{~mm}$, and with mild of CV for annual runoff 0.52 and with skewness of yearly flow of 0.75 and with value of 0.75 in great $\mathrm{CVs}$ for monthly scale. The highest and lowest variability in low runoff was 0.66 and 1.19 and the highest and lowest variability in peak runoff was 0.66 and 0.29 .

- Group two represented streams that placed on the south-east place of the island with small runoff values of $142 \mathrm{~mm}$, and with great of $\mathrm{CV}$ for annual runoff 0.87 and with skewness of yearly flow of 1.04 and with value of 0.87 in great $\mathrm{CVs}$ for monthly scale. The highest and lowest variability in low runoff was 0.67 and 1.14 .

- Group three displayed streams that placed on the south-western place of the island with great runoff values of $1,347 \mathrm{~mm}$, and with small of CV for annual runoff 0.23 and with skewness of yearly flow of 0.46 and with value of 0.49 in small CVs for monthly scale. The highest and lowest variability in low runoff was 0.67 and 0.44 .

- Group four represented streams that placed on the northern coast of Tasmania with great runoff values of $762 \mathrm{~mm}$, and with small of $\mathrm{CV}$ for annual runoff 0.36 and with skewness of yearly flow of 0.15 and with value of 0.65 in small CVs for monthly scale. The highest and lowest variability in low runoff was 0.91 and 0.54 . Also [52] improved the method in order to categorise run-off in ungauged places of Victoria region and applied the results for analysing ecological classifications. The analysis performed for 117 sub-basins in the area for daily time series for 15 years. The results of the study also understood the effect of great climate alteration on run-off and ecological aspects. In their work, the categorisation of run-off depended on two main factors include:

(1) the full flow record

(2) low flow

The categorisation related to entire flow generated five groups which had homogeneous distribution which depended on topography and climate features. However, the categorisation related to low flow generated four groups which had significant heterogeneous distribution [53]

In addition, in order to explain the relationship between hydrological categorisation and ecological aspects Mackay in 2014 applied multivariate techniques. Furthermore, Mackay et al. [35] with using multivariate techniques understood the connections between physical catchment features (include morphometric, vegetative cover, catchment area and underlying geology) and low discharge in ungauged places of South-Eastern Australia. The study area was small (with $250 \mathrm{~km}^{2}$ ) with 19 sub-catchments and the analysis performed for 17 years.

In another study, for analysing similarity in hydrological categorisation, several clustering techniques and several variable weighting applied [54]. However, another work applied Andrew's curves for recognising different groups. The study did not analyse the effect of spatial characteristics on the categorisation.

Another work performed for examining flow regime variation and making the similarity categorisation for South-Eastern Australian (Victoria to Southern Queensland). The work applied for 107 gauging sites for 20 years (in daily scale) [52]. The work used Gower metric of similarity to understand alterations within the regimes of controlled and uncontrolled streams. The results displayed that unregulated streams showed less similarity. 
Also Hydrological classification used for analyzing spatial alteration in hydrology and relationship with ecological factors in some streamflows of the Australia [4].

The study used 15 gauges (daily data) and redundancy analysis for the hydrological categorisation for 20 years period. The work standardised all variables before the examination.

The study which was done by McManamay et al. (2015) [55] a matrix used the Euclidean distance measure to categorise discharge. The matrix reached through "non-metric multidimensional scaling" and class mean assembling, correspondingly. The outcomes from the study showed several categorisations to understand differences in flashing discharge. The results represented that flashing discharge depended on seasonal discharge in wet and dry conditions.

In the Flinders River in Northern Australia, categorisation for flow regimes established on classification mean association cluster performed. The results showed that two main categorisations of flow found; natural and possibly modified regimes [56]. The research used the daily discharge data from 13 gauges for 20 years.

In Fitzroy River basin in Australia, categorisation for flow regimes also established on Euclidean distance and group mean linkage cluster performed. Also two statistical factors (CV of yearly streamflow and $\mathrm{CV}$ of the frequency of non flow days could lead the spatial variation and hydrological categorisation. Four landscape parameters include, elevation, average slope of the catchment, average precipitation and drainage density.

Could effect on spatial alteration in CV and zero flow days was. Therefore, four hydrological categorises found in the study:

(1) Permanent flow (the CV for this group was 0.80 and frequency of zero flow days was $0.06)$.

(2) Seasonal flow (the CV for this group was 0.82 and frequency of zero flow days was 0.46 )

(3) Dry seasonal flow (the CV for this group was 1.24 and frequency of zero flow days was $0.68)$.

(4) Seasonal periodic flow (the CV for this group was 1.74 and frequency of zero flow days was 0.86).

The study mentioned that if in one of the specific hydrologic group, two or more river gauges allocated, so the gauges identified as anomalous without similarity in climate and geology and flood forecasting or processes could not do properly in this condition because flood generation progressions usually related to large-scale meteorological progressions through the whole district.

\section{Discussion}

Various hydrological homogeneity method applied previously, in order to recognise hydrological categorization and regionalisation. The techniques comprise SOM, multivariate ordination, hard and soft categorization algorithms for example Bayesian and fuzzy clustering categorization and hierarchical and flat clustering algorithms.

This paper is the first work that reviewed all the previous and present various techniques accessible and the data requirements and progressions necessary to fulfill different techniques. This research applied a procedure for categorization which states problems concerning feature of information and coincidence, selection of categorization technique and estimation of outcomes.

However previous works only focused on one method. For instance, Alam et al. (2016) [57] in order to understand hydrological homogeneous zones and the relationship between the hydrological groups with regard to the water regime and its cooperation in land use planning, like the decline in climatic hazard in agriculture, livestock and forestry production. Their results showed that in the groups with a minor water balance decrease agricultural yield significantly, however in the groups with water surplus can raise the mass of crop yields and therefore can decrease the appearance of pests and illnesses which can effect the quality of the crops, considerably. Another research performed to categorise homogeneity of run off [58]. The study used cluster analysis (established on the monthly run off dispersal) and recognised 25 homogeneous run off zones. The research mentioned that run-off is the significant element that can effect on the greatest threat to agriculture, and the results of these analyses can help to establish proper agricultural organisation for growing crops in a particular district.

In order to examine the difference among homogeneous categorisations with regard to the stream flow regime in the Brazil (where usually average annual stream flow is higher than 2,750 mm), so Pappadà et al., (2018) [59] applied cluster examination, with Ward's hierarchical technique and the Euclidean distance. Their research recognised eight homogeneous categories with alike temporal stream flow dispersal aspects and emphasised the effect of orography and oceanic parameters for the maximum stream flow happening on the coastal area of the region.

Bharath and Srinivas (2015) [60] applied cluster analysis in order to categorise hydrologic 
parameter and recognise the highest run off regimes in Brazil. They found three different groups include:

(1) the first group showed great decline in run off especially in the winter months in the northern part of the region.

(2) the second group represented the highest annual run off with great homogeneity in monthly dispersal in the south-central and eastern parts of the region.

(3) the third group displayed lower annual run off (especially low run off concentration in the summer) south-eastern and northern parts of the region.

\section{Conclusion}

In this study, different techniques of hydrological homogeneity are explained and utilized in small and greater scale categorisations of flow regime however, the whole methods related to metric termination, extensiveness of hydrologic metrics applied, normalization of metrics and climatological techniques. Therefore, it can show the originality in this paper.

Previously, hydrologists only focused on one method for hydrological categorisation and analysed the effect of the categorisation on environmental aspects. For example, the previous works performed hydrological categorisation (based on similarities in hydrologic metrics) in ungauged basin to recognise the effect of hydrology homogeneity on ecology of an area.

However, this paper reviewed and compared various techniques for hydrology homogeneity. Also this study showed that in large-scale area, only small group of landscape and climatic aspects (as regionalisation parameters) can significantly effect on hydrology parameter (such as flow regime). So, only this small group can use for predicting changeability in a hydrologic parameter of an extreme event.

Establishing homogeneous groups for each region can allow to understand hydrological changeability and to realise the relationship among the parameters of stream flow fluctuation, oceanic influence, the orographic action of the region, and the regional atmospheric dynamics given the pluviometric spatial structure of the study area. This paper allowed acceptable application of various hydrological classification examination for understanding the interaction among the geographic elements of climate, emphasising the character played through the further parameters which can influence the maximum run off (or flooding) totals (especially in the coastal watershed) and the interference of regional atmospheric dynamics in the monthly run off dispersal.

\section{Data availability statement}

All data, models, and code generated or used during the study appear in the submitted article.

\section{References}

[1] Rodriguez RD, Singh VP, Pruski FF, et al. Using entropy theory to improve the definition of homogeneous regions in the semi-arid region of Brazil. Hydrological Sciences Journal, 2016, 61(11): 2096-2109. https://doi.org/10.1080/02626667.2015.1083651

[2] Olden JD, Kennard MJ and Pusey BJ. A framework for hydrologic classification with a review of methodologies and applications in ecohydrology. Ecohydrology, 2012, 5(4): 503-518. https://doi.org/10.1002/eco.251

[3] Latt ZZ, Wittenberg H and Urban B. Clustering hydrological homogeneous regions and neural network based index flood estimation for ungauged catchments: an example of the Chindwin River in Myanmar. Water Resources Management, 2015, 29(3): 913-928. https://doi.org/10.1007/s11269-014-0851-4

[4] Rolls RJ, Heino J and Chessman BC. Unravelling the joint effects of flow regime, climatic variability and dispersal mode on beta diversity of riverine communities. Freshwater Biology, 2016, 61(8): 1350-1364.

https://doi.org/10.1111/fwb.12793

[5] Kim Z and Singh VP. Assessment of environmental flow requirements by entropy-based multi-criteria decision. Water Resources Management, 2014, 28(2): 459-474. https://doi.org/10.1007/s11269-013-0493-y

[6] Oueslati O, De Girolamo AM, Abouabdillah A, et al. Classifying the flow regimes of Mediterranean streams using multivariate analysis. Hydrological Processes, 2015, 29(22): 4666-4682. https://doi.org/10.1002/hyp.10530 
[7] Huitema D and Meijerink S. The politics of river basin organizations: institutional design choices, coalitions, and consequences. Ecology and Society, 2017, 22(2): 1-22. https://doi.org/10.5751/ES-09409-220242

[8] Arikan BB and Kahya E. Homogeneity revisited: analysis of updated precipitation series in Turkey. Theoretical and Applied Climatology, 2017, 1(1): 1-10.

[9] Song X and Bai Y. A new empirical river pattern discriminant method based on flow resistance characteristics. Catena, 2015, 135(1): 163-172. https://doi.org/10.1016/j.catena.2015.07.026

[10] Novakova J, Melcakova I, Svehlakova H, et al. Hydro morphological assessment of the Porubka river. in IOP Conference Series: Earth and Environmental Science, IOP Publishing, October, 2017, 92(1): 012046. https://doi.org/10.1088/1755-1315/92/1/012046

[11] Booker DJ and Woods RA. Comparing and combining physically-based and empirically-based approaches for estimating the hydrology of ungauged catchments. Journal of Hydrology, 2014, 508(1): 227-239. https://doi.org/10.1016/j.jhydrol.2013.11.007

[12] Dollar ESJ, James CS, Rogers KH, et al. A framework for interdisciplinary understanding of rivers as ecosystems. Geomorphology, 2007, 89(1-2): 147-162. https://doi.org/10.1016/j.geomorph.2006.07.022

[13] Merwe J and Hellgren EC. Spatial variation in trophic ecology of small mammals in wetlands: support for hydrological drivers. Ecosphere, 2016, 7(11): 117-123 https://doi.org/10.1002/ecs2.1567

[14] Gao M, Chen X, Liu J, et al. Regionalization of annual runoff characteristics and its indication of co-dependence among hydro-climate - landscape factors in Jinghe River Basin, China. Stochastic Environmental Research and Risk Assessment, 2018, 32(6): 1613-1630. https://doi.org/10.1007/s00477-017-1494-9

[15] Stagnitta TJ, Kroll CN and Zhang Z. A comparison of methods for low streamflow estimation from spot measurements. Hydrological Processes, 2018, 32(4): 480-492. https://doi.org/10.1002/hyp.11426

[16] Kumari B, Paul PK, Singh R, et al. Regionalization study of satellite based hydrological model (SHM) in hydrologically homogeneous river basins of India. in EGU General Assembly Conference Abstracts, 2017, 19: 2538.

[17] Adams MD, Kanaroglou PS and Coulibaly P. Spatially constrained clustering of ecological units to facilitate the design of integrated water monitoring networks in the St. Lawrence Basin. International Journal of Geographical Information Science, 2016, 30(2): 390-404. https://doi.org/10.1080/13658816.2015.1089442

[18] Nepal S. Impacts of climate change on the hydrological regime of the Koshi river basin in the Himalayan region. Journal of Hydro-environment Research, 2016, 10(1): 76-89. https://doi.org/10.1016/j.jher.2015.12.001

[19] Poff NL, Olden JD, Merritt DM, et al. Homogenization of regional river dynamics by dams and global biodiversity implications. Proceedings of the National Academy of Sciences, USA, 2007, 104: 5732-5737.

https://doi.org/10.1073/pnas.0609812104

[20] McCuen RH. Modeling Hydrologic Change: Statistical Methods, Springer publication, CRC Press. 2016. https://doi.org/10.1201/9781420032192

[21] Mediero L, Kjeldsen TR, Macdonald N, et al. Identification of coherent flood regions across Europe by using the longest streamflow records. Journal of Hydrology, 2015, 528(1): 341-360. https://doi.org/10.1016/j.jhydrol.2015.06.016

[22] Beskow S, de Mello CR, Vargas MM, et al. Artificial intelligence techniques coupled with seasonality measures for hydrological regionalization of Q90 under Brazilian conditions. Journal of Hydrology, 2016, 541(1): 1406-1419. https://doi.org/10.1016/j.jhydrol.2016.08.046

[23] Javadinejad S, Dara R and Jafary F. Impacts of Extreme Events on Water Availability. Annals of Geographical Studies, 2019, 2(3): 16-24.

[24] Rinaldi M, Gurnell AM, Del Tánago MG, et al. Classification of river morphology and hydrology to support management and restoration. Aquatic Sciences, 2016, 78(1): 17-33. https://doi.org/10.1007/s00027-015-0438-z

[25] Radović T, Grujić S, Petković A, et al. Determination of pharmaceuticals and pesticides in river sediments and corresponding surface and ground water in the Danube River and tributaries in Serbia. Environmental Monitoring and Assessment, 2015, 187(1): 4092. https://doi.org/10.1007/s10661-014-4092-z

[26] Foufoula E, Ebtehaj AM and Bras RL. A novel Bayesian algorithm for microwave retrieval of precipitation from space: applications in snow and coastal hydrology. in EGU General Assembly Conference Abstracts, April, 2015, 17.

[27] Wang B, Mezlini AM, Demir F, et al. Similarity network fusion for aggregating data types on a genomic scale. Nature Methods, 2014, 11(3): 333 https://doi.org/10.1038/nmeth.2810

[28] Razavi S, Elshorbagy A, Wheater H, et al. Toward understanding nonstationarity in climate and hydrology through tree ring proxy records. Water Resources Research, 2015, 51(3): 1813-1830. https://doi.org/10.1002/2014WR015696 
[29] Chuan ZL, Ismail N, Shinyie WL, et al. The efficiency of average linkage hierarchical clustering algorithm associated multi-scale bootstrap resampling in identifying homogeneous precipitation catchments. in IOP Conference Series: Materials Science and Engineering, IOP Publishing, 2018, 342(1): 012070 .

https://doi.org/10.1088/1757-899X/342/1/012070

[30] Belletti B, Rinaldi M, Bussettini M, et al. Characterising physical habitats and fluvial hydromorphology: a new system for the survey and classification of river geomorphic units. Geomorphology, 2017, 283(17): 143-157.

https://doi.org/10.1016/j.geomorph.2017.01.032

[31] Lin GF and Wang CM. Performing cluster analysis and discrimination analysis of hydrological factors in one step. Advances in Water Resources, 2006, 29(11): 1573-1585. https://doi.org/10.1016/j.advwatres.2005.11.008

[32] Dronova I, Gong P, Wang L, et al. Mapping dynamic cover types in a large seasonally flooded wetland using extended principal component analysis and object-based classification. Remote Sensing of Environment, 2015, 158(1): 193-206. https://doi.org/10.1016/j.rse.2014.10.027

[33] Ley R, Hellebrand H, Casper MC, et al. Comparing classical performance measures with signature indices derived from flow duration curves to assess model structures as tools for catchment classification. Hydrology Research, 2016, 47(1): 1-14. https://doi.org/10.2166/nh.2015.221

[34] Koch J, Cornelissen T, Fang Z, et al. Inter-comparison of three distributed hydrological models with respect to seasonal variability of soil moisture patterns at a small forested catchment. Journal of Hydrology, 2016, 533(1): 234-249. https://doi.org/10.1016/j.jhydrol.2015.12.002

[35] Mackay SJ, Arthington AH and James CS. Classification and comparison of natural and altered flow regimes to support an Australian trial of the ecological limits of hydrologic alteration frameworki Ecohydrology, 2014, 7(6): 1485-1507. https://doi.org/10.1002/eco.1473

[36] Kuentz A, Arheimer B, Hundecha Y, et al. Understanding hydrologic variability across Europe through catchment classification. Hydrology and Earth System Sciences, 2017, 21(6): 2863-2879. https://doi.org/10.5194/hess-21-2863-2017

[37] West C, Wagener T and Rosolem R. A comparative hydrology approach to understand groundwater recharge variability across the African continent. in EGU General Assembly Conference Abstracts, 2018, 20: 9576.

[38] Fernandez R and Sayama T. Hydrological recurrence as a measure for large river basin classification and process understanding. Hydrology and Earth System Sciences, 2015, 19(4): 1919-1942. https://doi.org/10.5194/hess-19-1919-2015

[39] Tiner RW. Wetland Indicators: A Guide to Wetland Formation, Identification, Delineation, Classification, and Mapping, Springer publication, CRC Press. 2016.

[40] Gehlot S, Hagemann S and Brovkin V. Global distribution of riverine DOC concentration: coupling terrestrial carbon and lateral hydrology in MPI-ESM. in EGU General Assembly Conference Abstracts, 2018, 20: 13511 .

[41] Jones JAA. Global Hydrology: Processes, Resources and Environmental Management, Taylor \& Francis publication, Routledge. 2014.

[42] McMillan H, Montanari A, Cudennec C, et al. Panta Rhei 2013-2015: global perspectives on hydrology, society and change. Hydrological Sciences Journal, 2016, 61(7): 1174-1191. https://doi.org/10.1080/02626667.2016.1159308

[43] Almorox J, Quej VH and Martí P. Global performance ranking of temperature-based approaches for evapotranspiration estimation considering Köppen climate classes. Journal of Hydrology, 2015, 528(1): 514-522. https://doi.org/10.1016/j.jhydrol.2015.06.057

[44] Goyal MK and Gupta V. Identification of homogeneous rainfall regimes in Northeast Region of India using fuzzy cluster analysis. Water Resources Management, 2014, 28(13): 4491-4511. https://doi.org/10.1007/s11269-014-0699-7

[45] Webb JA, Bond NR, Wealands SR, et al. Bayesian clustering with AutoClass explicitly recognises uncertainties in landscape classification. Ecography, 2007, 30(4): 526-536. https://doi.org/10.1111/j.0906-7590.2007.05002.x

[46] Jarihani B, Sidle RC, Bartley R, et al. Characterisation of hydrological response to rainfall at multi spatio-temporal scales in savannas of semi-arid Australia. Water, 2017, 9(7): 540. https://doi.org/10.3390/w9070540

[47] Naghibi SA, Pourghasemi HR and Dixon B. GIS-based groundwater potential mapping using boosted regression tree, classification and regression tree, and random forest machine learning models in Iran. Environmental Monitoring and Assessment, 2016, 188(1): 44. https://doi.org/10.1007/s10661-015-5049-6

[48] Braaten R and Gates G. Groundwater-surface water interaction in inland New South Wales: a scoping study. Water Science and Technology, 2003, 48(7): 215-224. https://doi.org/10.2166/wst.2003.0443

[49] Cohen TJ, Jansen JD, Gliganic LA, et al. Hydrological transformation coincided with megafaunal extinction in central Australia. Geology, 2015, 43(3): 195-198. https://doi.org/10.1130/G36346.1 
[50] Lawson JR, Fryirs KA and Leishman MR. Hydrological conditions explain variation in wood density in riparian plants of South-eastern Australia. Journal of Ecology, 2015, 103(4): 945-956. https://doi.org/10.1111/1365-2745.12408

[51] Halliday BT, Matthews TG, Iervasi D, et al. Potential for water-resource infrastructure to act as refuge habitat. Ecological Engineering, 2015, 84(1): 136-148. https://doi.org/10.1016/j.ecoleng.2015.07.020

[52] Brown S. Assessing Spatio-temporal Hydrologic Variability: A Case-study in Western Victoria, $\mathrm{PhD}$, Deakin Univeristy. 2015.

[53] Boscarello L, Ravazzani G, Cislaghi A, et al. Regionalization of flow-duration curves through catchment classification with streamflow signatures and physiographic-climate indices. Journal of Hydrologic Engineering, 2015, 21(3): 05015027. https://doi.org/10.1061/(ASCE)HE.1943-5584.0001307

[54] Javadinejad S, Dara R and Jafary F. Potential impact of climate change on temperature and humidity related human health effects during extreme condition. Safety in Extreme Environments, 2020, 1-7. https://doi.org/10.1007/s42797-020-00021-x

[55] McManamay RA, Bevelhimer MS and Frimpong EA. Associations among hydrologic classifications and fish traits to support environmental flow standards. Ecohydrology, 2015, 8(3): 460-479. https://doi.org/10.1002/eco.1517

[56] Erskine W, Saynor M and Lowry J. Application of a new river classification scheme to Australia's tropical rivers. Singapore Journal of Tropical Geography, 2017, 38(2): 167-184. https://doi.org/10.1111/sjtg.12196

[57] Alam J, Muzzammil M and Khan MK. Regional flood frequency analysis: comparison of L-moment and conventional approaches for an Indian catchment. ISH Journal of Hydraulic Engineering, 2016, 22(3): 247-253. https://doi.org/10.1080/09715010.2016.1177739

[58] Shein EV, Kiryushin VI, Korchagin AA, et al. Assessment of agronomic homogeneity and compatibility of soils in the Vladimir Opolie region. Eurasian Soil Science, 2017, 50(10): 1166-1172. https://doi.org/10.1134/S1064229317100118

[59] Pappadà R, Durante F, Salvadori G, et al. Clustering of concurrent flood risks via hazard scenarios', Spatial Statistics, 2018, 23(1): 124-142. https://doi.org/10.1016/j.spasta.2017.12.002

[60] Bharath R and Srinivas VV. Delineation of homogeneous hydrometeorological regions using waveletbased global fuzzy cluster analysis. International Journal of Climatology, 2015, 35(15): 4707-4727. https://doi.org/10.1002/joc.4318 